\title{
DIKÉ E TÊMIS 1
}

Josiane Boulad-Ayoub

Departamento de Filosofia da Universidade de Quebeque, Canadá

Bjarne Melkevik

Faculdade de Direito da Universidade de Laval, Canadá

Pierre Robert

Departamento de Ciências Jurídicas da Universidade de Quebec, Canadá

Recebimento em 14/06/2017

Aceito em 26/08/2017

\section{O DIREITO E A LEI: GENEALOGIA JURÍDICA PARA EXPLICAR UM CONFLITO DE GERAÇÕES}

Enquanto o título deliberadamente provocador deste colóquio, "O Amor das Leis", é quase um lugar comum para constatar o declínio da lei ou até mesmo para proclamar a sua decadência, esse mesmo título coloca indubitavelmente a questão das relações entre o direito e a lei, entre a justiça e a lei. Trata-se, aqui, menos de relações afetivas, como poderia sugerir a expressão inspirada em "O Espírito das Leis", de Montesquieu, do que de laços de filiação entre o direito e a lei. A crise da lei moderna pode assim ser concebida como um conflito de gerações, comportando antagonismos e tensões, como também laços familiares e, algumas vezes, sobrevivência do amor filial.

\footnotetext{
${ }^{1}$ Traduzido por Nevita Maria Pessoa de Aquino Franca Luna, Alessandra Correia Lima Macedo Franca e Maria das Neves Pessoa de Aquino Franca. Nota das tradutoras: Originalmente, o presente texto constituía o prefácio à obra BOULAD-AYOUB, Josiane; MELKEVIK, Bjarne; ROBERT, Pierre (dirs). L'Amour des lois. La crise de la loi moderne dans les sociétés démocratiques. Québec et Paris: Presses de l'Université Laval et L'Harmattan, 1996, que reuniu algumas das intervenções oferecidas durante um colóquio acadêmico de mesmo título, realizado no Canadá. A opção por traduzir e publicar aquele prefácio deveuse, segundo as tradutoras, à atualidade, clareza e didatismo com que os autores abordam temas tão caros à filosofia e teoria do direito contemporâneas. As tradutoras agradecem, em especial, a atenção e gentileza do Prof. Dr. Bjarne Melkevik pela autorização de publicação e pela atenção dedicada à revisão deste texto.
} 


\section{A TEOGONIA DE HESÍODO: FILIAÇÃO E OPOSIÇÕES ${ }^{2}$}

Têmis, deusa grega da lei eterna, torna-se, por sincretismo, a personificação da justiça. Filha do Céu e da Terra, de Urano e de Gaia, ela era da família dos Titãs. Têmis, portanto, faz parte da terrível geração dos Urânios, estas espécies descendentes do Céu e da Terra: os Titãs, os Ciclopes e os Gigantes, que representam as forças brutas e primitivas da natureza e da primeira humanidade. A natureza original desta deusa simboliza bem a lei como potência bruta, como a expressão fria de uma regulação imposta pela natureza ou pela força: a lei constitutiva da ordem.

Têmis foi a segunda esposa de Zeus, o Rei dos deuses e dos homens. Zeus era seu sobrinho, por parte de pai, Chronos, e de mãe, Rhéa, dois titãs. Pelos laços do matrimônio, Têmis participa, portanto, da segunda geração das divindades da mitologia grega e acede ao panteão olímpico.

Esta união reflete a associação do poder e da lei. A luta épica que Zeus tinha antecipadamente travado com os Titãs, depois com os Gigantes, simbolizava sua conquista do poder e o estabelecimento de sua dominação sobre a família dos deuses. Este relato representa, assim, o triunfo da ordem e da lei sobre as forças selvagens do instinto e da brutalidade. Aliás, Têmis está diretamente associada a esta vitória sobre os seus irmãos hecatônquiros [ou centimanos], já que é sob as ordens dela (Têmis), que Zeus se veste com a Égide, a pele da cabra Amalteia que se mostra uma couraça impenetrável. Essa narrativa mitológica evoca, portanto, a imagem da ordem que sob a égide da lei luta contra o crime.

Atribuía-se a Têmis a invenção dos oráculos, dos ritos e das leis. O conjunto das características que compõem a personalidade de Têmis indica claramente o dogma da origem divina da Lei e explica a aura de sacralidade que cerca a enunciação das regras de conduta do grupo pelo chefe do génos, o Rei:

A têmis é o apanágio de basileús [do chefe], que é de origem celeste, e o plural temistas indica o conjunto dessas prescrições, código inspirado pelos deuses, leis não escritas, coletânea de ditos, de vereditos dados pelos oráculos, que

\footnotetext{
${ }^{2}$ Para o texto da Théogonie: Hésiode et les poètes élégiaques et moralistes de la Grèce, tradução por E. Bergougnan, Paris, Librarie Garnier. Para os detalhes mitológicos: P. Commelin, Mythologie grecque et romaine, Paris, Librarie Garnier, 1956; P. Grimal, Dictionnaire de la Mythologie grecque et romaine, Paris, P.U.F., 1951.
} 
fixam na consciência do juiz (no caso, o chefe da família) a conduta a se considerar todas as vezes que a ordem do génos está em jogo ${ }^{3}$.

A linguística e a antropologia ${ }^{4}$ demonstram suficientemente o estreitamento dos laços entre a lei, a religião e o poder político nos direitos arcaicos de modo que é supérfluo tratar aqui em detalhe dessas relações. A Têmis é, então, a Lei editada por um poder. Por suas características, Têmis só corresponde a uma única dimensão do fenômeno jurídico. Ela não é todo o direito, ainda que ela possa constituir uma ordem jurídica.

Para além disso, a narrativa mitológica continua. De sua união com Zeus, Têmis gerou as Horas, as Moiras e a Virgem Astreia, outra personificação da Justiça, agora idealizada, visto que Astreia brilha inacessível na Constelação da Virgem. As Moiras, que os Romanos identificaram como Parcas, são as três irmãs que cuidam dos destinos humanos.

A tríade das Horas (Orai) reunia Diké, Eunomia e Irene. Essas deusas simbolizam coletivamente a ordem na natureza e, em seguida, a ordem na sociedade. Esta terceira geração olímpica permite afinar a concepção da Justiça e do Direito. Eunomia que personifica a Disciplina ou a Boa Ordem, evoca pela etimologia a obediência à regra e representa, portanto, a obediência às leis e à conformidade jurídica e normativa. Irene simboliza a Paz indispensável à prosperidade. Ela é a única das Horas que possui uma iconografia que lhe é própria, pois estas divindades são preferencialmente abstratas nos seus atributos sociais.

Na mitologia, Diké simboliza o sentimento de Justiça e o Direito na sociedade. Este sentido abstrato e geral deriva, entretanto, de significados anteriores às conotações mais técnicas. O estudo do vocábulo Diké por Beneviste demonstra claramente a vinculação da palavra ao vocabulário jurídico grego ${ }^{5}$. A raiz deiknumi evoca a ideia de aplicação do direito: mostrar com autoridade aquilo que deve ser. É a aplicação das

\footnotetext{
${ }^{3}$ É. Benveniste, Le vocabulaire des instituitions indo-européennes, Tome 2. Pouvoir, droit, religion, Paris, Les Éditions de Minuit, 1969. p. 103. No original: "La thémis est l'apanage de basileús, qui est d'origine céleste, et le pluriel thémistes indique l'ensemble de ces prescriptions, code inspiré par les dieux, lois non écrites, recueil de dits, d'arrêts rendus par les oracles, qui fixent dans la conscience du juge (en l'espèce, le chef de la famille) la conduite à tenir toutes les fois que l'ordre du génos est en jeu".

${ }^{4}$ É. Benveniste citado na nota precedente, ver especificamente G. Glotz, La solidarité de la famille dans le droit criminel en Grèce, Paris, Albert Fontemoing, 1904, reimp. New York, Arno Press, 1973, p. 21 e ss.; G. Timsit, Les figures du jugement, Paris, P.U.F., 1993, p. 45 e ss.; A. Garapon, L'âne portant des reliques, essai sur le rituel judiciaire, Paris, Éditions du Centurion, 1985, p. 175 e ss.

${ }^{5}$ É. Benveniste, op. cit., capítulo 2. Dikè, p. 107-110.
} 


\section{REVITA ACDEMAICA

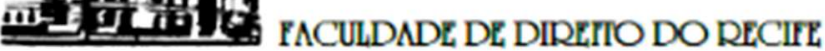

soluções postas à prova, as fórmulas do direito, os dikai, pelo juiz que as protege (o dikaspolos homérico é aquele que vela os dikai). O verbo “dizer" em latim, dico, dicere, possui a mesma raiz indo-européia que diké. A palavra jus dicere, dizer o direito, está na origem da palavra judiciário.

Em oposição a Têmis, Diké, divindade mais inacessível, evoca a ideia mais abstrata do Direito. Filha de Têmis, Diké se refere necessariamente às leis e às regras imperativas cuja aplicação são vigiadas por sua mãe. Entretanto, Diké representa mais que a personificação da função judiciária. A Diké engloba ao mesmo tempo o poder judiciário de determinação das regras aplicáveis segundo o caso, como também um Saber constituído pelo acúmulo das decisões de Justiça: o Direito e o Costume. Este sentido é dado pelo significado atribuído ordinariamente a diké: "hábito" [uso], "modo de ser" que de poderia completar por "utilização das leis" e "modo de ser submisso à lei", em suma o direito costumeiro.

Enfim, a última característica que a opõe a Têmis é que Diké opera a dessacralização do jurídico em relação à ordem social, à sociedade humana e ao papel do juiz:

diké e ius se referem, ao contrário, à palavra humana, às fórmulas - dikai, iura - que o juiz pronuncia quando ele as aplica aos casos determinados com os quais é confrontado. Aqui se encontra fundada a primeira distinção - ela é essencial - da palavra humana - aquela do juiz - e da palavra impessoal aquela dos deuses: toda palavra impessoal - aquela do povo por exemplo, vox populi - vendo-se deste fato reconhecido valor divino: vox populi, vox dei... ${ }^{6}$

Este esboço mitológico faz ressaltar, graças à sua dimensão simbólica, os laços de filiação entre a Lei e o Direito. O exame das significações do mito revela entretanto as relevantes oposições entre Diké e Thêmis que confirmam a história do direito grego da Antiguidade.

\footnotetext{
${ }^{6}$ G. Timsit, op. cit., p. 47. No original: [...] diké et ius, se referent au contraire à la parole humaine aux formules - dikai, iura - que prononce le juge lorsqu'il les applique au cas determinés auxquels il est confronte. Par là se trouve fondée la première distinction - elle est essencielle - de la parole humaine celle du juge - et de la parole impersonnelle - celle des dieux: toute parole impersonnelle - celle du peuple par exemple, vox populi - se voyant de ce fait reconnaître valeur divine: vox populi, vox dei...
} 


\section{O MITO DE PROTÁGORAS: DISTINÇÕES E RECONCILIAÇÃO}

$\mathrm{Na}$ Grécia arcaica, a têmis corresponde à ordem jurídica intrafamiliar. Trata-se de uma justiça doméstica que repousa entre as mãos do chefe da família. O detentor do poder doméstico enuncia e aplica a Lei do clã à sua parentela. A origem divina da autoridade do chefe do génos confere à lei sua característica imperativa. A família inteira é solidária à execução da lei e o contraventor é punido sem qualquer forma de processo além da palavra autoritária do chefe do clã.

A Diké corresponde à emergência progressiva de uma ordem jurídica interfamiliar para solucionar os conflitos entre grupos sociais diferentes. A situação é então totalmente diferente já que a têmis familiar não pode se aplicar ao estrangeiro: é o reino da vingança privada que, para que ela não degenere em revanche, toma o lugar, inspirada pela diké, da palavra mediadora do juiz, conciliador e árbitro. Na sua forma original, a diké é, inicialmente, mediação a fim de apaziguar os conflitos e restabelecer a Paz. Na teogonia de Hesíodo "o rei justo, quando ele avança na assembleia, pronto apaziguar a desmedida (Hubris), pela sabedoria doce de seu verbo, é saudado por todos como deus"7.

Esta intervenção do terceiro na resolução dos conflitos constitui uma primeira transição na ordem jurídica. A diké está ainda na esfera da vingança privada, mas ela intervém pelo sistema da composição entre a família da vítima e do acusado.

A segunda transição da ordem jurídica consagra a passagem da vingança privada à vingança pública, da responsabilidade coletiva à responsabilidade individual. A diké opera esta passagem instituindo a jurisdição social que abre, segundo a expressão de Salas, espaço para uma palavra compartilhada e comum, o espaço da diké.

Ao instaurar o espaço do debate, a diké permite o distanciamento entre a lei e sua execução. A determinação da responsabilidade pelo juiz permite assim a consideração e o respeito da pessoa humana. O debate judiciário permite o desenvolvimento do raciocínio jurídico e o reconhecimento progressivo dos princípios do Direito cujas exigências judiciárias e rituais foram as primeiras expressões.

\footnotetext{
${ }^{7}$ Théogonie, 91; ver J.-P Vernant, Mythe et pensée chez les grecs. Études de psychologie historique, Paris, François Maspero, 1965, p. 28; sobre as significações e a interpretação histórica de Têmis e Diké na antiguidade grega, mais da obra fundamental de G. Glotz, pré-citada, ver dois textos notáveis de D. Salas, Du procès penal. Éléments pour une théorie interdisciplinaire du procès, Paris, P.U.F., 1992, particularmente as p. 57-59; "État et droit penal. Le droit penal entre 'thémis' e 'dikè'” in: Droits, $\mathrm{n}^{\circ} 15$, 1992, p. 77; igualmente M. Weber, Sociologie du droit, Paris, P.U.F., 1986.
} 
A terceira transição consiste no reinado de Diké ou no primado do direito. Glotz expos como na Antiguidade os progressos do Direito Penal Ateniense (pelo desenvolvimento do processo acusatório e pela instituição do Júri e das assembleias) estão estritamente associados ao desenvolvimento da democracia. A Diké consiste assim no desenvolvimento de um direito humano, Direito do Homem. Este laço entre direito e democracia, entre processo e justiça, corresponde bem à Diké, este sentimento do direito e da Justiça indissociável da vida social como lembra o mito de Protágoras ${ }^{8}$. Zeus, constatando as lutas intermináveis dos homens entre si, e a fim de impedir a desaparição deles, envia Hermes para lhes levar dois dons. Esses presentes tinham o propósito de tornar possível a vida em sociedade, a constituição das cidades, em suma de tornar acessível aos homens a prática da arte política. Esses dois dons foram aidôs e diké: Diké, aqui, tem o sentido do respeito aos direitos do outro. É um sentido da justiça que permite a paz civil, submetendo os litígios às decisões judiciais 9 .

Hermes pergunta então a Zeus se ele deve distribuir estes dons, o sentimento de honra (ou pudor) e o sentimento da justiça, a todos ou a alguns. Zeus ordena que eles sejam partilhados entre todos os homens. Tal é a missão da justiça.

\section{CONCLUSÃO: OS CICLOPES ATEMISTAS}

Logo no curso de sua odisseia, Ulisses e seus companheiros atracam na ilha dos ciclopes e lá reencontram Polifemo que não pratica a hospitalidade, capturando-os e devorando dois dentre eles. Homero, pela intervenção de seu personagem Ulisses, descreve os Ciclopes como seres que "não conhecem nenhum lugar onde se delibera (diké), nem leis (têmis)”, brutos selvagens “dotados de uma grande força, monstros sem respeito à Justiça (diké) e às leis (têmis)". Face à barbárie humana, às guerras intra ou inter-estados, aos terrorismos e às violações dos direitos do homem, os laços de filiação

\footnotetext{
${ }^{8}$ Para uma análise dos laços entre a Diké e o mito de Protágoras, ver I. F. Stone, Le procès de Socrate, Paris, Odile Jacob, 1990, p. 60-61. Ver igualmente J. de Romilly, La loi dans la pensée grecque des origines à Aristote, Paris, Les Belles Lettres, 1971, p. 85.

${ }^{9}$ I. F. Stone, op. cit., p.60. No original: "Diké, ici, a le sens du respect des droits d'autrui. C'est un sens de la justice qui permet la paix civile en soumettant les litiges aux décisions judiciares."
} 


\section{TH REVISTA ACADÊMICA

da lei e do direito se renovam. A negação do direito e o menosprezo às leis recriam a necessidade do amor às leis.

Pierre Robert

\section{O AMOR ÀS LEIS}

O presente texto é fruto do colóquio interdisciplinar $\mathrm{O}$ Amor às Leis que aconteceu em Montreal em abril de 1995. No âmbito da reflexão atual em filosofia e teoria jurídica sobre as tendências do Direito nas sociedades pluralistas contemporâneas, as diversas contribuições apresentadas no colóquio analisaram a evolução do direito face à crise que atravessa as relações com a lei e entre as leis. Essas contribuições havidas no colóquio se distinguiram, nós acreditamos, por quatro características essenciais, todas inéditas até o momento no Quebec, a saber:

- Uma problemática atual, dinâmica, original: as análises e os debates tratam em efeito sobre o tema, a crise da lei moderna nas sociedades democráticas, que ainda não foi abordado desta maneira em nenhum lugar, ao nosso conhecimento.

- Uma perspectiva interdisciplinar com a qual foi conduzida, ao longo do percurso, tanto a reflexão como o ensaio de síntese intitulado Crise, crítica, prospectiva com o qual se encerrou o colóquio $^{10}$. Foi a primeira vez no Canadá que se tentou a conjunção/cruzamento de pesquisadores provenientes de várias disciplinas diferentes e, principalmente, o encontro entre filósofos e juristas.

- Uma avaliação da internacionalização da pesquisa ligada à reflexão sobre os problemas postos pela evolução do direito e as tendências jurídicas em uma sociedade pluralista.

- Uma contribuição prática à política de colaboração interuniversitária/organismos governamentais e à política de diálogo interinstitucional no quadro canadense.

\footnotetext{
10 Trata-se, na verdade, de uma mesa redonda presidida pela Sra. Juíza Anne-Marie Trahan, sobre a qual foi concluído o colóquio de abril. Contrariamente aos outros, as transcrições do registro das comunicações de dois autores, René Degny Seguy e Patrice Vermeren, não foram objeto de uma nova redação, por diversas razões. No entanto, eles foram revisados e verificados por J. Boulad-Ayoub.
} 


\section{TH REVISTA ACADÊMICA

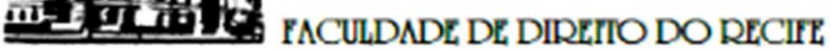

Mais especificamente, nós tentamos colmatar uma lacuna importante no discurso científico sobre questão da lei: para os pesquisadores, a ausência de uma sistematização crítica das análises que tratam sobre a crise da lei assim como o desinteresse destes mesmos pesquisadores para sensibilizar, informar e orquestrar os debates públicos sobre esses problemas, que estão no coração das relações sociais, culturais e políticas. Além disso, diante deste silêncio e da separação tradicional entre disciplinas, nós pretendemos reunir, em torno de um centro de gravidade específico, dando sua unidade à reflexão comum, pesquisadores trabalhando em centros de filosofia jurídica e política, de início nas universidades através do Canadá, mas também na França, como aquelas de Paris XNanterre e de Aix-en-Provence; nós entendemos a lei posta, ao mesmo tempo, como vínculo social e força simbólica de representação do liame cultural e coletivo. Nós visamos assim fecundar reciprocamente as abordagens no domínio da filosofia e da teoria do direito, assim como favorecer a síntese heurística das análises que, mais frequentemente, ficam a despeito de suas características aparentes, confinadas nos limites dos domínios disciplinares onde elas se aplicam.

A unidade da problemática se tece pelo horizonte de três questões: o declínio ou a desafeição à lei, a crise da lei, o desafio posto à lei; todos pontos sobre os quais se orientam os debates e a reflexão. Parte-se do diagnóstico da crise da lei nos estados ocidentais modernos, crise que se manifesta tanto no plano das relações dos cidadãos com a lei e o Estado, quanto no plano da reflexão contemporânea sobre a lei. Primeiramente, são sublinhadas as causas desta crise, identificando os debates e as referências conceituais e ideológicas às quais os autores coletivos e individuais se referem e que orientam suas representações e tomadas de posições contrárias (amor da lei, hostilidade, indiferença, desinteresse, deslocamento...). Em seguida, são avaliadas as manifestações diversas que esta crise se reveste: o impacto cultural, institucional e social que ela pode ter sobre as transformações da nossa modernidade jurídica e política.

Nós vivemos, com efeito, uma situação de crise. De um lado, nós podemos observar uma indiferença social diante da inflação das leis. De outro lado, nós podemos constatar a sensibilidade do estado a uma certa crítica que prega a desjudicialização, desregulamentação e a auto-regulação. A questão da Lei não parece mais o primeiro objeto de reflexão nas nossas sociedades. Como conseguimos abandonar a reflexão sobre este aspecto central da modernidade jurídica e política? Quais são as causas desta perda 
de credibilidade e de autoridade da lei, as fontes deste fenômeno de dessacralização? O liberalismo econômico, ao querer diminuir a lei jurídica a uma simples e dócil formulação da lei econômica, e o marxismo, desenvolvendo e espalhando a ideia que toda lei jurídica é apenas a expressão pura e simples dos interesses da classe dominante, contribuiu cada um para ocultar os aspectos simbólicos e culturais da lei, que concorrem para forjar, desde o sucesso da revolução democrática, esta disposição do cidadão ao amor às leis, como amor cívico à igualdade, à liberdade e à fraternidade.

Pela lei e pela instituição parlamentar, outrora magníficas na sua função emblemática de representação da vontade geral, trata-se incontestavelmente de um processo de relativização de seus papéis simbólicos e políticos. A extensão planetária do estado de direito é a expressão mais bem sucedida desta tendência, pois é doravante o juiz que é a figura central, em seu duplo papel de guardião e de guia responsável da conformidade da lei às normas constitucionais.

O primeiro tema de reflexão, a lei em questão, é pretexto para se formular um diagnostico. As contribuições reagrupadas sob este tema relacionam-se com a identificação dos diversos motivos desta crítica, assim como os sintomas desta desafeição. Elas examinam, passo a passo, as razões internas do direito (multiplicação das regras de direito, mediocridade das normas jurídicas, perdas pelo direito de suas qualidades tradicionais ligadas à estabilidade, à permanência, à universalidade, à certeza, à autoridade...); as razões políticas e sociais (a utilização política da lei, o tratamento mediático da lei e de seus processos, as liberdades contra a lei, a ineficácia da lei, a disfunção da lei...); as razões institucionais (crise do status do direito, crise do Estado social, crises dos modelos da regulação social...); enfim as razões culturais (confusão entre simbólico e ideológico, mutação das estruturas, ascensão das reivindicações identitárias, crise da universalidade, degradação das solidariedades, aumento de um individualismo hedonista, crise do idealismo, do positivismo, do formalismo jurídicos...).

Não é, todavia, questão de parar diante da simples constatação da crise da lei. A reflexão mobiliza para discutir as funções, as diversas concepções, representações e imagens da lei como liame social e fermento de transformação.

Aquelas mesmas que nos legaram os grandes pensadores da modernidade política, jurídica e filosófica desde Montesquieu a Rosseau, Kant e Condorcet. Este último não escreveu nada senão: “É preciso que, amando-se as leis, se saiba julgá-las”. O segundo 
tema de reflexão trata precisamente das representações da lei. Aqui as contribuições trazem a tona as principais questões simbólicas, políticas e culturais que atravessam o discurso sobre o espírito da lei e que orientam a relação dos cidadãos com a lei e com o Estado sob diversos modos (concepções, imagens, valores, linguagens...) e os diversos graus de apropriação das leis como próprio bem. A discussão sobre a significado da lei se ordena assim em torno das funções simbólicas (carácter transcendente da lei, filonomia, misonomia, fraternidade, solidariedade, igualdade jurídica, religião natural, particularismos culturais, exigências normativas da democracia...), das funções políticas (liberdade, pluralismo, justiça, tolerância, a ideia nacional, a cidadania, o estrangeiro, as situações de trabalho, as minorias étnicas e religiosas, as mutações do Estado...), das funções filosóficas e científicas (ética da responsabilidade, o sujeito de direito, a noção da lei, a competência racional, os modelos universalista, utilitarista, liberal, comunitário, a pragmática da linguagem, a teoria da ação, os processos de objetivação do mundo vivido...), e enfim das funções teóricas (formas alternativas de resolução dos conflitos sociais, a decisão e a justificação da decisão, a racionalidade jurídica, as atitudes cognitivas e emocionais, a aplicação da lei...).

A esta pesquisa sobre a natureza da lei moderna e a esta crítica do significado da lei junta-se uma dimensão prospectiva. Trata-se de explorar as pistas ao nível discursivo e ao nível das práticas que são atualmente suscetíveis de se abrir em direção a uma recomposição, uma reformulação da lei levando em consideração as controvérsias teóricas pertinentes e a evolução sócio-jurídica contemporânea. Esta vontade de repensar a função da lei implica na assunção das responsabilidades de sua redefinição, assim como a colocação a prova das forças que ela encobre no dinamismo destes processos de institucionalização: a perpetuação, a garantia bem como a renovação dos valores e dos ideais sociais. As contribuições que alimentam o terceiro tema, o pensamento prospectivo, a modernidade da lei e as transformações do direito, têm o firme compromisso com a visão de futuro. Esta empreendendo as mutações das práticas teóricas e jurídicas contemporâneas, tenta repensar a função da lei moderna face às novas dinâmicas sociais. O debate se articula assim em torno do novo contrato social e das transformações do direito para tratar do papel e do funcionamento da lei no modelo democrático, assim como dos fundamentos filosóficos e das transformações políticas, jurídicas e sociais. 


\section{DAS ERÍNIAS ÀS EUMÊNIDAS}

Retornamos agora para concluir este texto a um passado remoto. Os filósofos acreditam seguramente na convocação de Platão e na recordação do mito que ele contou a Protágoras. Decepcionemos-lhes. No lugar de Zeus que envia por Hermes aos homens "o sentimento da honra e aquele do direito a fim de que estes sentimentos fossem o adorno das cidades e o laço pelo qual se unem as amizades" (Protágoras, 322 c), recorramos às deusas, ao mito e ao poeta..

Quando se está na área do mito, duas poderosas figuras são associadas ao nascimento da História, duas figuras que, cada uma à sua maneira, convocam nas origens do Pacto social, uma o conflito, outra as leis. Somente quando a violência é contida pelo direito a humanidade pode ingressar, senão na paz, ao menos na direção do apaziguamento das instituições. Através desta longa marcha ritmada por Ares que é a vida dos homens em sociedade.

A mais bela das Nereidas, contam os gregos, era Thétis, cortejada em casamento ao mesmo tempo por Zeus e Poseidon . Têmis, no entanto, tendo declarado que Thétis daria luz a um filho que seria mais poderoso que seu próprio pai (que era Aquiles), os dois deuses renunciaram ao projeto e preferiram casar Thétis com um mortal, o lendário rei de Myrmidon, Peleu, filho de Éaque, famoso por sua piedade e justiça. As bodas foram celebradas com grande pompa e na presença de todos os deuses que cobriram os nubentes de presentes magníficos. Mas, Eris, a Discórdia, furiosa por não ter sido convidada, lança na sala onde estavam reunidos os convivas uma maçã (ou pomo) com a inscrição: “À Mais Bela".

Héra, Athéna e Afrodite reivindicam-na e, para resolver a disputa, remetem-na, sob as ordens de Zeus, ao julgamento de Paris, filho de Príamo, que, sobre o monte Idha, guardava as tropas de seu pai.

A maçã lançada por Éris no meio dos imortais, reunidos para celebrar o nascimento dos filhos e netos das divindades primordiais, vai desencadear uma sucessão de acontecimentos que dão origem à Guerra de Tróia, ou seja, a história dos Gregos, e pelos descendentes de Eneias, filho de Anquise, que se refugia na Itália, dá-se origem à tradição das raízes troianas dos Romanos. 
A simbólica tal qual ela nos foi legada pelo discurso do mito e da epopeia é sugestiva. No início da historicidade, ela conjuga de uma só vez a união e a desunião, os regozijos de bodas lendárias e os conflitos, à princípio imediatos entre os deuses, futuros, em seguida, entre os homens. Gregos e troianos verão, com a eclosão da guerra epônima, cantada por Homero, o mundo deles entrar em colapso, mas também se reproduzir, graças a outras uniões-desuniões. No centro do ciclo troiano, tais como relatadas originalmente na Ilíada e na Odisseia, obras que foram por excelência as primeiras preceptoras da história da humanidade, os cantos que relatam a alternância das noites terríveis e dos dias radiantes que os povos conheceram, a guerra de Troia.

Porém, por mais imensa que seja, a guerra ocupa apenas uma parte deste díptico alegórico que nós nos ocuparemos de encenar. Nós apelaremos à potência do dramaturgo para completar a outra parte da alegoria. Ao lado das forças que desencadeiam a violência e o conflito no meio da Festa, arrancando o banquete da ordem eterna do amor, está o irmão de Peleu, Orestes, e como pares de Eris ou de Afrodite, Atena e Apolo acompanhados por Diké. A socialização começa pela mediação deles e pela metamorfose das Erínias ${ }^{11}$ em Eumênidas.

Ésquilo, com As Eumênidas, completa o ciclo da Orestíada. Aqui o poeta recita a descida das Leis ao mundo dos Homens; as Leis sem as quais a liberdade, a justiça, a virtude permanecem submissas aos caprichos de Eris. Sob o impulso de Atena que representa (com Apolo) os novos deuses, Apolo cede ao Estado e ao distinto tribunal do Areópago $^{12}$, o arbítrio da causa de Orestes que matou Egistro e Clitemnestro. Os arcontes se aproveitam da dúvida de Orestes, enquanto Atena alerta as Erínias que é tempo de fazer cessar seus ressentimentos e de se inclinar diante das instituições judiciarias e religiosas de Atenas. As Erínias apaziguadas tornam-se as Eumênidas, as Benevolentes. Elas serão doravante tão devotas à cidade que as honrar sob esta nova forma (as Leis) quanto eram hostis, se superando de amor e de zelo pela cidade que as acolhe, aumentando sua glória e prosperidade.

\footnotetext{
${ }^{11}$ Nota das tradutoras: As erínias eram as deusas encarregadas de castigar os crimes, especialmente os delitos de sangue. Elas são também chamadas Eumênides (Eủ $\mu \varepsilon v i ́ \delta \varepsilon \varsigma$ ), que em grego significa as bondosas ou as benevolentes, eufemismo usado para evitar pronunciar o seu verdadeiro nome, por medo de atrair sobre si a sua cólera.

12 Assim como o Areópago é o modelo dos tribunais; a Pnyx, lugar de reunião da assembleia do povo, é o antepassado dos parlamentos. O nascimento das leis corresponde ao início da racionalização política. Os novos legisladores humanos substituem os deuses para codificar a Cidade segundo as normas de igualdade. O Mito engendra a História, e, ao seu turno, a História vai engendrar os novos mitos.
} 
Aqui está o que declara Atena no momento sublime em que o direito (Diké) é

instituído no mesmo lugar da guerra e da antiga vingança.

Ouçam agora a lei que eu estabeleço, cidadãos da Ática, que deve julgar os primeiros processos sobre sangue derramado. Este conselho de juízes subsistirá sempre no futuro do povo de Egeu. Ele terá sede sobre esta colina de Ares, onde as Amazonas se estabeleceram e fincaram suas tendas, quando, com ódio de Teseu, trouxeram até aqui a guerra e, em frente à acrópole, elas levantaram as torres de uma nova cidade e sacrificaram Ares, de onde veio o nome de Areópago deste rochedo. Sobre esta colina, o Respeito e o Temor, seu irmão, impedirão os cidadãos, de noite como de dia, de cometerem crimes, contanto que eles não alterem suas leis. Se se contamina uma fonte límpida com fluxos impuros e lama, não se encontrará mais o que beber. Nem anarquia, nem despotismo, tal é a máxima que eu aconselho os cidadãos de praticar e de venerar, e também de não banir todo o temor da cidade; pois que mortal permanecerá justo, se ele não duvidar de nada? Si vocês reverenciarem, como devem, este poder augusto, vocês terão para proteger vosso país e vossa cidade uma muralha tal qual não há no mundo, nem nos povos Citas, nem sobre o solo de Pélope. Incorruptível, venerável, impiedoso, sentinela acordado para proteger a cidade adormecida, tal será o tribunal que eu instituo. Se eu desenvolvi por longo tempo meus conselhos, é no interesse futuro dos habitantes da minha cidade. Agora, é preciso levantar-vos, levar vosso voto e decidir o processo, respeitando vosso juramento. Eu disse. ${ }^{13}$

Sob a proteção de Atena a (re)ge(ne)ração do social deve seguir a (re)ge(ne)ração das leis. É nesta condição que a tirania ou o arbítrio da antiga ordem serão contidos e substituídos pelas regras da nova ordem humana. Éris tem as rédeas puxadas pelas Eumênidas, ou seja, pelas leis.

13 Eschyle, Les Euménides, p. 681-710, in: Théâtre, edição de É. Chambry, Paris, Garnier, 1946. No original: "Écoutez maintenant la loi que je fonde, citoyens d'Athènes, vous qui pour la première fois jugez un cas de sang versé. Ce conseil de juges subsistera toujours dans l'avenir chez le peuple d'Égée. Il siégera sur cette colline d'Arès, où les Amazones s'établirent et plantèrent leurs tentes, lorsque en haine de Thésée, elles apportèrent ici la guerre et fortifièrent de tours cette nouvelle ville contre les hautes tours de l'ancienne. Là elles sacrifièrent à Arès, d'où vint à ce rocher le nom d'Aréopage. Sur cette colline, le Respect et la Crainte, sa soeur, empêcheront les citoyens, la nuit comme le jour, de commettre des crimes, pourvu qu'ils n'altèrent point leurs lois. Si l'on souille une source limpide d'afflux impurs et de boue, on n'y trouvera plus de quoi boire. Ni anarchie, ni despotisme, telle est la règle que je conseille aux citoyens de pratiquer, de vénérer, et aussi de ne point bannir toute crainte de la ville; car quel mortel reste juste, s'il ne redoute rien ? Si vous révérez, comme vous le devez, ce pouvoir auguste, vous aurez là pour protéger votre pays et votre ville un rempart tel qu'il n'en est pas au monde, ni chez les Scythes ni sur le sol de Pélops. Incorruptible, vénérable, impitoyable, sentinelle éveillée pour garder la cité endormie, tel sera le tribunal que j'institue. Voilà les avis que j'ai longuement développés à l'intention des habitants de ma ville pour les jours à venir. Maintenant il faut vous lever, porter votre suffrage et trancher le procès, en respectant votre serment. J'ai dit." 
Foi assim que tudo começaria: no início da História, Éris e a guerra, no início da cidade civilizada, Atena e a instituição das leis e do direito, esta prosa do mundo como chamava Hegel. Nosso díptico que desenvolve o ciclo humano e o início da democracia, sob a dupla marca das bodas de Thétis e Peleu, a Festa, e da metamorfose das Erínias em Eumênidas, as leis, está relativamente irmanado com essas incontáveis ficções simbólicas que, de Platão a Rousseau, presidem o nascimento da cidade, do soberano e do governo; a passagem do homem da natureza ao homem da cultura.

O tempo do mito é repentinamente quebrado. Fingimos crer em um momento em que há um mito e que há um tempo, uma pré-história, um pré-tempo ou um não-tempo. Cortar o tempo em um antes e um depois. Um antes idílico, o tempo do mito, a era de ouro, um depois atormentado, o tempo da história cuja violência é mais ou menos civilizada pelas leis. De fato, o que nós queremos dizer é ao mesmo tempo mais simples e mais complicado.

A transformação das Erínias em Eumênidas, das velhas deusas que reinavam antes de Zeus, das Fúrias encarregadas de punir os parricidas, nestas divindades Benevolentes que são as Leis, guardiãs da cidade, desejando prever que os atenienses respeitem o altar da Justiça, é tudo isto que se apresenta, como pretende simbolizar o poeta, para prestar contas da paz ateniense e da democracia de Péricles? Para celebrar a origem de um direito novo, menos rigoroso do que concebiam as velhas deusas, mais humano, tomando em conta o arrependimento e as circunstâncias atenuantes? Sem dúvida, se se quer fazer esquecer que o mesmo Péricles (e Efialtes), com a finalidade de uma reforma demagógica, tinha subtraído da jurisdição do Areópago, dois anos antes da representação de Orestíada, seu direito de censura e de fiscalização sobre todos os atos da vida pública, reduzindo suas atribuições ao julgamento dos crimes capitais, homicídios, incêndio, impiedade. Se comodamente se negligencia de ver que esse magnífico elogio da justiça ateniense é destinado também, segundo as intenções mesmas de Ésquilo, a prevenir os atenienses contra as novas violações que poderiam ainda ser trazidas pelos democratas ao nobre tribunal.

É a cultura que dá um sentido à história que ela tece, e é a ideologia (o mito?) que controla nos diversos registros da cultura, ontológico, axiológico, pragmático, seus ritmos políticos. Prescreve o que é e o que não é, o que é bem e o que é mal, o que se deve fazer ou não se deve; impondo o que se deve ler, dizer, crer. A história, ou seja, a cultura e a 


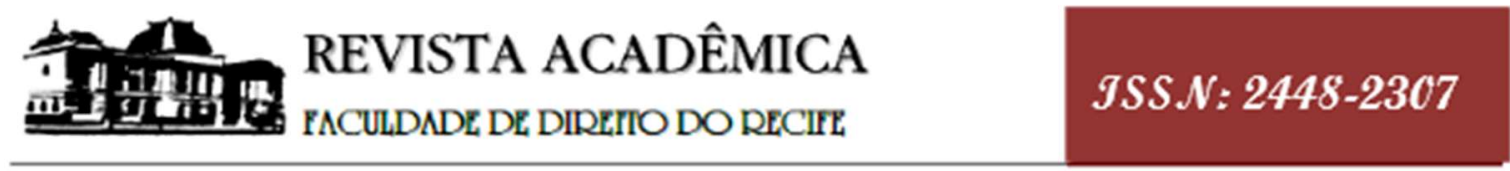

sociedade, tem um começo, a ideologia, isto é, as lutas contra o poder, isto é, a guerra; e sonha com um fim, ou seja, a paz perpetua, a paz que visam as leis e as instituições dos homens. Este sonho bem ordenado, sempre perseguido, e sem cessar adiado, é talvez a história ela mesma. A violência é a ordem do dia até a vitória da República e da democracia, até a paz, ou sem dúvida até a morte. 